\title{
Chemoselective Luche-Type Reduction of $\alpha, \beta$-Unsaturated Ketones by Magnesium Catalysis
}

\author{
Yoon Kyung Jang, ${ }^{\dagger}$ Marc Magre, ${ }^{*} \dagger$ and Magnus Rueping ${ }^{*}, \dagger, \ddagger$ \\ ${ }^{\dagger}$ Institute of Organic Chemistry, RWTH Aachen University, Landoltweg 1, 52074 Aachen, Germany \\ ${ }^{\ddagger}$ KAUST Catalysis Center (KCC), King Abdullah University of Science and Technology (KAUST), Thuwal 23955-6900, Saudi \\ Arabia
}

Supporting Information

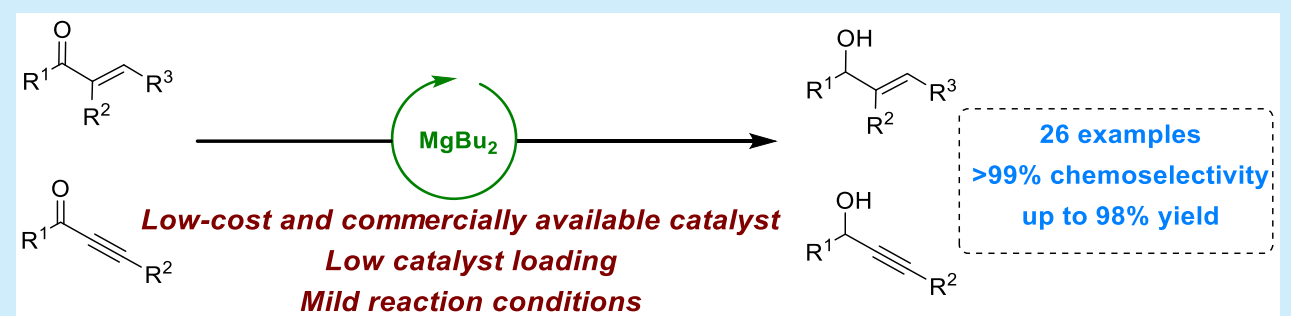

ABSTRACT: The chemoselective reduction of $\alpha, \beta$-unsaturated ketones by use of an economic and readily available $\mathrm{Mg}$ catalyst has been developed. Excellent yields for a wide range of ketones have been achieved under mild reaction conditions, short times, and low catalyst loadings $(0.2-0.5 \mathrm{~mol} \%)$.

$\mathrm{T}$ raditionally, the selective reduction of $\alpha, \beta$-unsaturated $\mathrm{C}=\mathrm{O}$ bonds has been achieved using stoichiometric amounts of metal hydrides, ${ }^{1}$ such as $\mathrm{NaBH}_{4}$ and stoichiometric amounts of Lewis acid, for instance, $\mathrm{CeCl}_{3} \cdot 7 \mathrm{H}_{2} \mathrm{O}$ in the Luche reduction (Scheme 1a). ${ }^{2}$ Additionally, transition-metal-catalyzed high-pressure hydrogenations have been applied. ${ }^{3,4}$ In this respect, in recent decades, the use of pinacolborane (HBpin) as a mild and sustainable carbonyl group reductant has attracted attention. ${ }^{5,6}$ While the hydroboration of polarized bonds such as ketones and aldehydes has been achieved, the reduction of $\alpha, \beta$-unsaturated ketones remains challenging due to problems associated with the chemoselectivity $(\mathrm{C}=\mathrm{O}$ vs unsaturated CC bond reduction). ${ }^{5}$

The application of alkaline-earth abundant metals in catalysis has attracted interest as an alternative to transitionmetal-catalyzed processes. ${ }^{7-9}$ In spite of their abundance in the Earth's crust, low toxicity, and low cost, their application has

Scheme 1. $\mathrm{MgBu}_{2}$-Catalyzed Chemoselective Hydroboration of Ketones

a) Traditional method: Luche Reduction

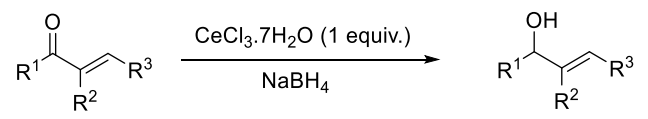

b) This work

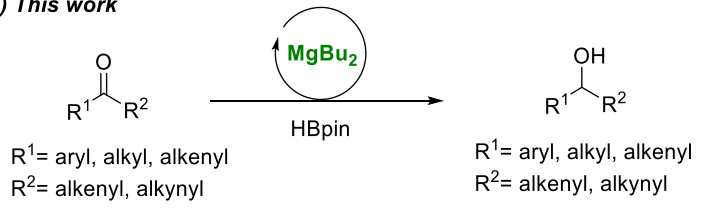

Table 1. Reaction Optimization for the Mg-Catalyzed Hydroboration of Enone $1 a^{a}$<smiles>CC(=O)/C=C/c1ccccc1</smiles>

$1 \mathbf{a}$

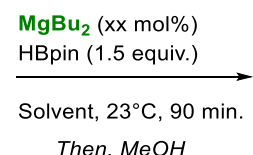

Then, $\mathrm{MeOH}$

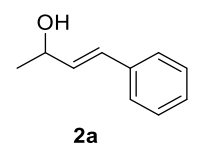

$2 a$

$\begin{array}{cclc}\text { entry } & \mathrm{MgBu}_{2}(\mathrm{~mol} \%) & \text { solvent } & \text { yield }^{b}(\%) \\ 1 & 2 & \text { toluene } & >95 \\ 2 & 2 & \text { THF } & >95 \\ 3 & 2 & \text { DCM } & >95 \\ 4 & 1 & \text { toluene } & >95 \\ 5 & 0.5 & \text { toluene } & >95 \\ 6 & 0.2 & \text { toluene } & \mathbf{9 5}(\mathbf{9 3}) \\ 7 & \text { none } & \text { toluene } & 0\end{array}$

${ }^{a}$ General conditions: 1a ( $\left.0.5 \mathrm{mmol}\right), \mathrm{HB}$ in ( 1.5 equiv), $\mathrm{MgBu}_{2}(0.5$ $\mathrm{M}$ heptane solution), solvent (1 M), $23{ }^{\circ} \mathrm{C}$ for $90 \mathrm{~min}$. ${ }^{b}$ Yields determined by ${ }^{1} \mathrm{H}$ NMR using 1,3,5-trimethoxybenzene as internal standard. Isolated yield in parentheses.

been limited to a few catalytic transformations. ${ }^{7}$ In this regard, magnesium catalysis has been limited to the hydrofunctionalization of polarized and unpolarized unsaturated bonds. ${ }^{10-12}$ However, a general and synthetically applicable magnesiumcatalyzed hydroboration protocol for the chemoselective reduction of both enones and ynones and propargylic ketones with low catalyst loading has not been reported. Recently, we developed the selective hydroboration of terminal and internal

Received: September 3, 2019

Published: October 7, 2019 
Scheme 2. Scope for the $\mathrm{MgBu}_{2}$-Catalyzed Hydroboration of Enones ${ }^{a}$

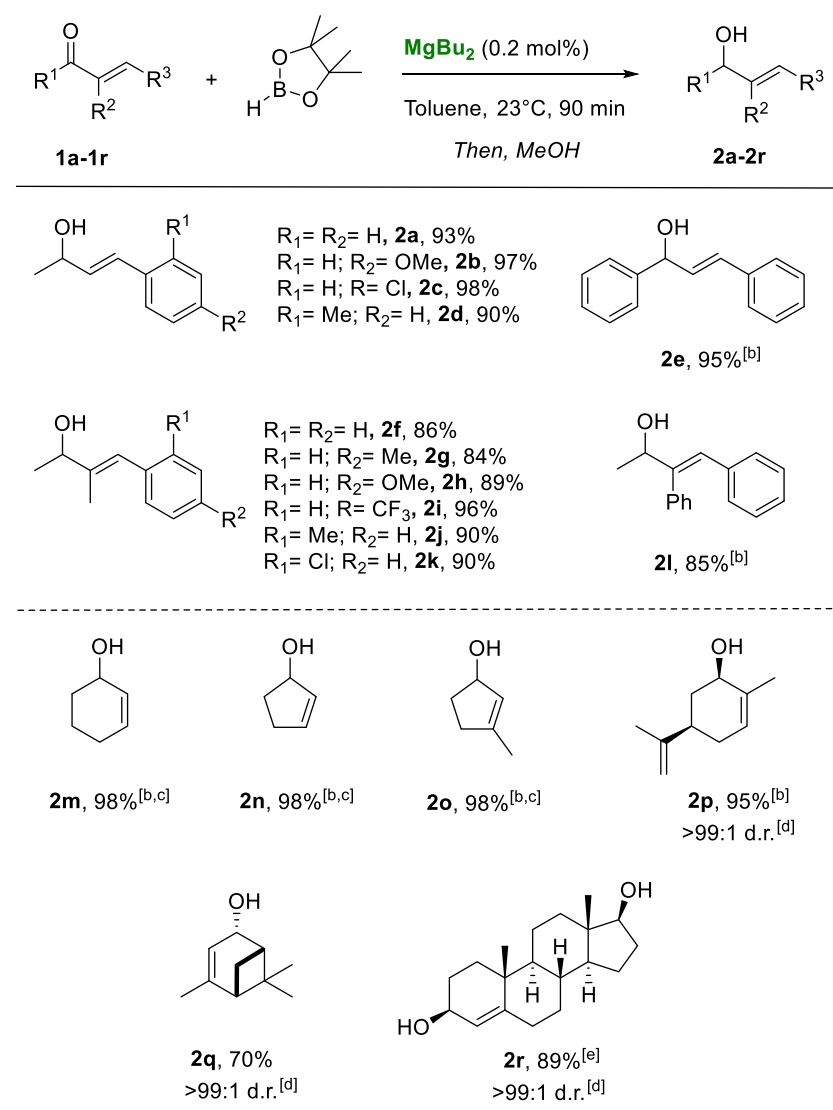

${ }^{a}$ General conditions: $\mathbf{1 a}-\mathbf{1 r}(0.5 \mathrm{mmol}), \mathrm{HBpin}$ (1.5 equiv), $\mathrm{MgBu}_{2}$ ( $0.2 \mathrm{~mol} \%, 0.5 \mathrm{M}$ heptane solution), solvent $(1 \mathrm{M}), 23{ }^{\circ} \mathrm{C}$ for 90 min. Isolated yields. ${ }^{b} \mathrm{MgBu}_{2}(0.5 \mathrm{~mol} \%)$ for $2 \mathrm{~h}$. ${ }^{c}$ Yield determined by ${ }^{1} \mathrm{H}$ NMR of the boronic ester. ${ }^{d}$ Diastereoselectivity determined by ${ }^{1} \mathrm{H}$ NMR. Absolute configurations were determined by comparison with literature values. ${ }^{e} 2.5$ equiv of $\mathrm{HB}$ pin was used.

alkynes using low-cost and commercially available $\mathrm{MgBu}_{2}$ as an efficient catalyst. ${ }^{13}$ Despite the circumstances where the latter reaction allowed the reduction of carbon-carbon multiple bonds, we decided to examine a chemoselective magnesiumcatalyzed reduction of enones and ynones since a successful accomplishment of such a method would be a valuable alternative to the existing protocols. Hence, chemoselectivity would be the key to a successful development of such a protocol.

Herein, we present the application of readily available $\mathrm{MgBu}_{2}$ as an efficient catalyst for the chemoselective hydroboration of $\alpha, \beta$-unsaturated ketones. Moreover, we prove that $\mathrm{MgBu}_{2}$ is not only active for the hydroboration of alkynes but can also be chemoselective toward $\mathrm{C}=\mathrm{O}$ reduction for propargylic ketones by fine-tuning the reaction conditions (Scheme 1b).

We started our investigation by using $\mathrm{MgBu}_{2}$ as catalyst, HBpin as reducing agent, and ketone $1 \mathbf{a}$ as model substrate (Table 1). Different solvents were examined at ambient temperature (Table 1, entries 1-3). However, we found that the choice of solvent had no influence on the catalytic activity. We were pleased to see that the catalyst loading could be decreased (Table 1, entries 4-6) to yield product 2a quantitatively by using only $0.2 \mathrm{~mol} \%$ of $\mathrm{MgBu}_{2}$. In the
Scheme 3. Scope and Limitations for the $\mathrm{MgBu}_{2}$-Catalyzed Hydroboration of Propargylic Ketones ${ }^{a}$

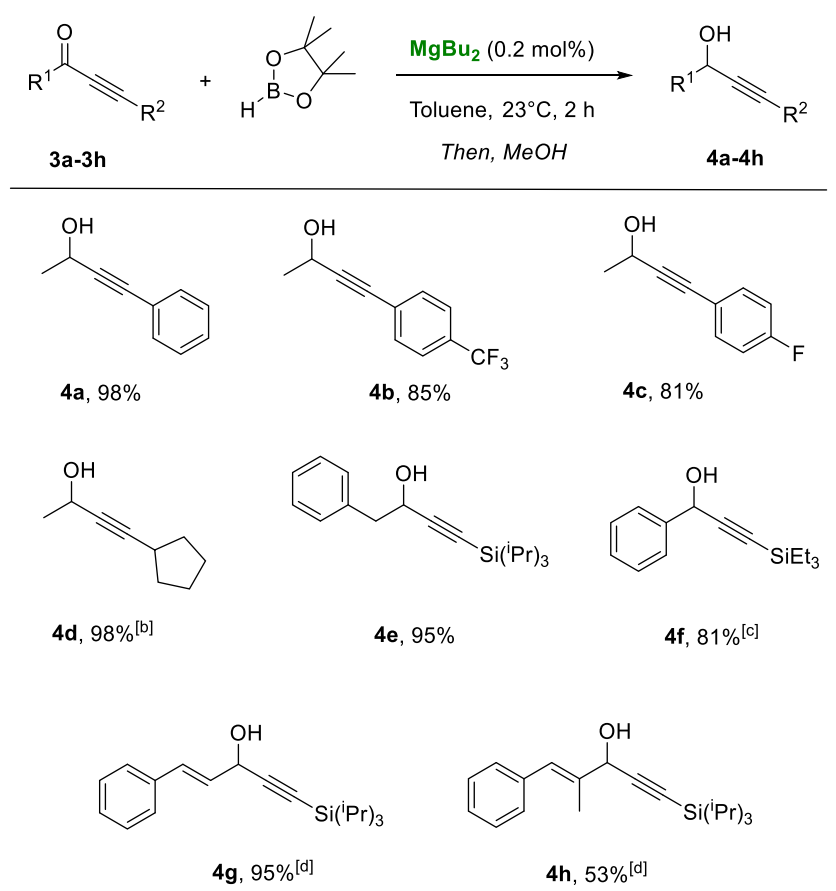

${ }^{a}$ General conditions: $3 \mathbf{a}-3 \mathbf{h}(0.5 \mathrm{mmol}), \mathrm{HBpin}$ (1.5 equiv), $\mathrm{MgBu}_{2}$ ( $0.2 \mathrm{~mol} \%, 0.5 \mathrm{M}$ heptane solution), solvent $(1 \mathrm{M}), 23^{\circ} \mathrm{C}$ for $2 \mathrm{~h}$. Isolated yields. ${ }^{b}$ Yield determined by ${ }^{1} \mathrm{H}$ NMR of the boronic ester. ${ }^{c} \mathrm{MgBu}_{2}$ (0.5 mol \%). ${ }^{d} \mathrm{MgBu}_{2}(0.5 \mathrm{~mol} \%)$ for $5 \mathrm{~h}$.

Scheme 4. Large-Scale Transformation

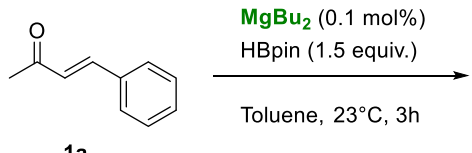

$1 \mathrm{a}$

$1.46 \mathrm{~g}(10 \mathrm{mmol})$

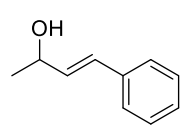

2a

$1.40 \mathrm{~g}, 94 \%$ yield absence of the catalyst (Table 1, entry 7) no desired product was observed.

With the optimized conditions in hand, we decided to study the scope and limitations of our catalytic system (Scheme 2). The good performance observed for benzylideneacetone 1a could be extended to other substrates with different electronic and steric properties $(\mathbf{1 b}-\mathbf{1 d})$. In this case, allylic alcohols $\mathbf{2 b}-\mathbf{2 d}$ were isolated in excellent yields. Likewise, we observed that trans-chalcone 1e underwent reduction selectively and in excellent yields. We also studied various $\alpha, \beta$-unsaturated ketones containing a substituent in the $\alpha$-position $(\mathbf{1 f}-\mathbf{1 1})$. The presence of different electronic and steric substituents in the aromatic ring $(\mathbf{1 f}-\mathbf{1 k})$ and the $\alpha$-position (11) did not dramatically affect the selective reduction, affording the corresponding allylic alcohols $(\mathbf{2 f}-\mathbf{2 l})$ in good-to-excellent yields. We also tested our $\mathrm{MgBu}_{2}-\mathrm{HB}$ pin catalytic system for the selective reduction of cyclic $\alpha, \beta$-unsaturated ketones. In all cases $(\mathbf{2} \mathbf{m}-\mathbf{2 o})$, excellent yields and selectivities could be achieved for 5- and 6-membered rings and also with a substituent present in the $\beta$-position. Finally, we studied the selective hydroboration of natural $\alpha, \beta$-unsaturated ketones such as (1S)-(-)-verbenone $\mathbf{1} \mathbf{p},(-)$-carvone $\mathbf{1 q}$, and testosterone 1r. We were pleased to see that in all cases the corresponding allylic alcohols could be isolated in good-to- 
Scheme 5. Control Experiment and Proposed Mechanism for the $\mathrm{MgBu}_{2}$-Catalyzed Chemoselective Hydroboration of $\boldsymbol{\alpha}, \boldsymbol{\beta}$-Unsaturated Ketones

a) Formation of active BuMgH species

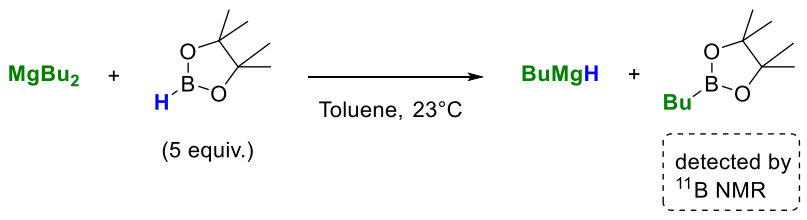

b) Proposed mechanism

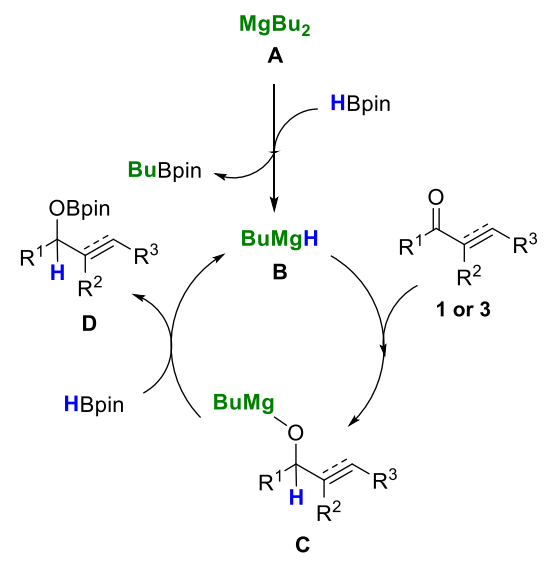

excellent yields, chemoselectivities, and diastereoselectivities. We were delighted to see that our commercially available alkaline earth metal-based catalyst competes favorably with the best reports to date using transition-metal catalysts. ${ }^{6}$ Thus, we decided to expand the catalytic system by testing the reduction of propargylic ketones (Scheme 3).

We observed that the Mg-catalyzed hydroboration of propargylic ketones was effective for a wide range of substrates, bearing different aromatic $(\mathbf{3 a}-\mathbf{3 c})$ as well as alkyl groups (3d). We also found out that propargylic ketones bearing different silyl groups $(\mathbf{3 e}-\mathbf{3 f})$ were tolerated. Finally, we could also demonstrate the high chemoselectivity of $\mathrm{MgBu}_{2}$, by selectively reducing substrates $3 \mathrm{~g}$ and $3 \mathrm{~h}$ bearing not only an alkynyl but also an alkenyl group. In both cases, excellent chemoselectivities were obtained.

Previously, our group demonstrated the high activity that commercially available $\mathrm{MgBu}_{2}$ presents toward the hydroboration of terminal and internal alkynes. ${ }^{13}$ Herein, we prove that by fine-tuning the reaction conditions $\mathrm{MgBu}_{2}$ can also be selective toward $\mathrm{C}=\mathrm{O}$ reduction for propargylic ketones.

The practical applicability of the $\mathrm{MgBu}_{2}-\mathrm{HB}$ pin catalytic system is demonstrated by performing the chemoselective reduction of model substrate benzylideneacetone $1 \mathrm{a}$ at a 10 mmol scale (Scheme 4). In this case, by using only $0.1 \mathrm{~mol} \%$ of low cost $\mathrm{MgBu}_{2}$, allylic alcohol $2 \mathrm{a}$ can be isolated in quantitative yield after $3 \mathrm{~h}$.

Regarding the mechanism, when mixing $\mathrm{MgBu}_{2}$ and $\mathrm{HBpin}$, an active $\mathrm{BuMgH}$ species is formed along with BuBpin (Scheme 5a). Thus, we propose a mechanism for the chemoselective magnesium-catalyzed hydroboration of unsaturated ketones as depicted in Scheme 5b. Commercially available $\mathrm{MgBu}_{2}$ A reacts with $\mathrm{HBpin}$ to generate active $\mathrm{BuMgH}$ species B. This active species undergoes hydromagnesiation of $\mathrm{C}=\mathrm{O}$ bond of ketone $\mathbf{1}$ or 3 , providing the corresponding $\mathrm{Mg}$ alkoxide species C. Finally, HBpin regenerates active $\mathrm{BuMgH}$ A species to afford the corresponding boronic ester $\mathbf{D}$ which undergoes hydrolysis in the presence of methanol, providing the allylic or propargylic alcohols 2 and 4.

In summary, we report a Luche-type reduction of $\alpha, \beta$ unsaturated ketones catalyzed by low cost and commercially available $\mathrm{MgBu}_{2}$. Good yields and chemoselectivities have been achieved for a wide range of ketones, including linear and cyclic substrates and natural products, showing the great versatility and group tolerance that the $\mathrm{MgBu}_{2}-\mathrm{HB}$ pin system presents. Moreover, the low catalyst loading (0.1-0.5 mol \%) and the short reaction times highlight the high activity of the $\mathrm{Mg}$ catalyst for the reduction of enones as well as ynones, and thus, the method represents a valuable alternative to existing procedures.

\section{ASSOCIATED CONTENT}

\section{Supporting Information}

The Supporting Information is available free of charge on the ACS Publications website at DOI: 10.1021/acs.orglett.9b03131.

Experimental procedures, characterization and NMR spectra (PDF)

\section{AUTHOR INFORMATION}

\section{Corresponding Authors}

*E-mail: marc.magre@oc.rwth-aachen.de.

*E-mail: magnus.rueping@rwth-aachen.de.

ORCID $\odot$

Yoon Kyung Jang: 0000-0002-9227-8995

Magnus Rueping: 0000-0003-4580-5227

Notes

The authors declare no competing financial interest.

\section{REFERENCES}

(1) (a) Hudlicky, M. Reductions in Organic Chemistry; Ellis Horwood Ltd.; Chichester, U.K., 1984; pp 96-175. (b) Abdel-Magid, A. F., Ed. Reductions in Organic Chemistry. Recent Advances and Practical Applications; ACS Symposium Series; American Chemical Society: Washington, DC, 1998.

(2) (a) Luche, J. L. J. Am. Chem. Soc. 1978, 100, 2226-2227. (b) Forkel, N. V.; Henderson, D. A.; Fuchter, M. J. Green Chem. 2012, 14, 2129-2132.

(3) Clarke, M. L.; Roff, G. J. Handbook of Homogeneous Hydrogenation; de Vries, J. G., Elsevier, C. J., Eds.; Wiley-VCH: Weinheim, 2007; pp 413-454.

(4) For selected examples, see: (a) Farnetti, E.; Pesce, M.; Kaspar, J.; Spogliarich, R.; Graziani, M. J. Chem. Soc., Chem. Commun. 1986 , 746-747. (b) Abdur-Rashid, K.; Lough, A. J.; Morris, R. H. Organometallics 2001, 20, 1047-1049. (c) de Koning, P. D.; Jackson, M. M.; Lennon, I. C. Org. Process Res. Dev. 2006, 10, 1054-1058. (d) Wang, M.-M.; He, L.; Liu, Y.-M.; Cao, Y.; He, H.-Y.; Fan, K.-N. Green Chem. 2011, 13, 602-607. (e) Mérel, D. S.; Elie, M.; Lohier, J.-F.; Gaillard, S.; Renaud, J.-L. Chem CatChem 2013, 5, 29392945. (f) Spasyuk, D.; Vicent, C.; Gusev, D. G. J. Am. Chem. Soc. 2015, 137, 3743-3746. (g) Dub, P. A.; Scott, B. L.; Gordon, J. C. J. Am. Chem. Soc. 2017, 139, 1245-1260.

(5) For selected reviews, see: (a) Chong, C. C.; Kinjo, R. ACS Catal. 2015, 5, 3238-3259. (b) Shegavi, M. L.; Bose, S. K. Catal. Sci. Technol. 2019, 9, 3307-3336.

(6) For selected examples of metal-catalyzed hydroboration of $\alpha, \beta$ unsaturated ketones, see: Zirconium catalysis: (a) Eedugurala, N.; Wang, Z.; Chaudhary, U.; Nelson, N.; Kandel, K.; Kobayashi, T.; 
Slowing, I. I.; Pruski, M.; Sadow, A. D. ACS Catal. 2015, 5, 7399-

7414. Nickel catalysis: (b) Chen, F.; Zhang, Y.; Yu, L.; Zhu, S. Angew. Chem., Int. Ed. 2017, 56, 2022-2025. Lanthanide catalysis: (c) Chen, S.; Yan, D.; Xue, M.; Hong, Y.; Yao, Y.; Shen, Q. Org. Lett. 2017, 19, 3382-3385. (d) Weidner, V. L.; Barger, C. J.; Delferro, M.; Lohr, T. L.; Marks, T. J. ACS Catal. 2017, 7, 1244-1247. For rare-earth metal catalysis, see: (e) Song, P.; Lu, C.; Fei, Z.; Zhao, B.; Yao, Y. J. Org. Chem. 2018, 83, 6093-6100. Actinide catalysis: (f) Ghatak, T.; Makarov, K.; Fridman, N.; Eisen, M. S. Chem. Commun. 2018, 54, 11001-11004. Aluminum catalysis: (g) Woodside, A. J.; Smith, M. A.; Herb, T. M.; Manor, B. C.; Carroll, P. J.; Rablen, P. R.; Graves, C. R. Organometallics 2019, 38, 1017-1020. Iron catalysis: (h) Zhang, G.; Cheng, J.; Davis, K.; Bonifacio, M. G.; Zajaczkowski, C. Green Chem. 2019, 21, 1114-1121. Cobalt catalysis: (i) Tamang, S. R.; Bedi, D.; Shafiei-Haghighi, S.; Smith, C. S.; Crawford, C.; Findlater, M. Org. Lett. 2018, 20, 6695-6700.

(7) For recent reviews on the use of organomagnesium complexes as catalysts, see: (a) Crimmin, M. R.; Hill, M. S. Top. Organomet. Chem. 2013, 45, 191-241. (b) Revunova, K.; Nikonov, G. I. Dalton Trans 2015, 44, 840-866. (c) Rochat, R.; Lopez, M. J.; Tsurugi, H.; Mashima, K. ChemCatChem 2016, 8, 10-20. (d) Hill, M. S.; Liptrot, D. J.; Weetman, C. Chem. Soc. Rev. 2016, 45, 972-988. (e) Pellissier, H. Org. Biomol. Chem. 2017, 15, 4750-4780. (f) Yang, D.; Wang, L.; Li, D.; Wang, R. Chem. 2019, 5, 1108-1166.

(8) For deprotonation/metalation reactions using magnesium organometallics, see: (a) Dong, Z.; Clososki, G. C.; Wunderlich, S. H.; Unsinn, A.; Li, J.; Knochel, P. Chem. - Eur. J. 2009, 15, 457-468. (b) Piller, F. M.; Bresser, T.; Fischer, M. K. R.; Knochel, P. J. Org. Chem. 2010, 75, 4365-4375. (c) Haag, B.; Mosrin, M.; Ila, H.; Malakhov, V.; Knochel, P. Angew. Chem., Int. Ed. 2011, 50, 97949824. (d) Benischke, A. D.; Ellwart, M.; Becker, M. R.; Knochel, P. Synthesis 2016, 48, 1101-1107.

(9) For $\beta$-diketiminate magnesium complexes in $\mathrm{C}-\mathrm{H}$ and $\mathrm{C}-\mathrm{F}$ activations, see: (a) Davin, L.; McLellan, R.; Kennedy, A. R.; Hevia, E. Chem. Commun. 2017, 53, 11650-11653. (b) Davin, L.; McLellan, R.; Hernán-Gómez, A.; Clegg, W.; Kennedy, A. R.; Mertens, M.; Stepek, I.; Hevia, E. Chem. Commun. 2017, 53, 3653-3656.

(10) For representative examples using $\mathrm{Mg}$ catalysts for the hydroboration of unsaturated bonds, see: (a) Arrowsmith, M.; Hadlington, T. J.; Hill, M. S.; Kociok-Kohn, G. Chem. Commun. 2012, 48, 4567-4569. (b) Arrowsmith, M.; Hill, M. S.; Kociok-Köhn, G. Chem. - Eur. J. 2013, 19, 2776-2783. (c) Mukherjee, D.; Ellern, A.; Sadow, A. D. Chem. Sci. 2014, 5, 959-964. (d) Fohlmeister, L.; Stasch, A. Chem. - Eur. J. 2016, 22, 10235-10246. (e) Rauch, M.; Ruccolo, S.; Parkin, G. J. Am. Chem. Soc. 2017, 139, 13264-13267. (f) Magre, M.; Maity, B.; Falconnet, A.; Cavallo, L.; Rueping, M. Angew. Chem., Int. Ed. 2019, 58, 7025.

(11) Mukherjee, D.; Shirase, S.; Spaniol, T. P.; Mashima, K.; Okuda, J. Chem. Commun. 2016, 52, 13155-13158.

(12) Manna, K.; Ji, P.; Greene, F. X.; Lin, W. J. Am. Chem. Soc. 2016, 138, 7488-7491.

(13) Magre, M.; Maity, B.; Falconnet, A.; Cavallo, L.; Rueping, M. Angew. Chem., Int. Ed. 2019, 58, 7025-7029. 